\title{
A cross sectional survey on social, cultural and economic determinants of obesity in a low middle income setting
}

Ambepitiyawaduge Pubudu De Silva ${ }^{1 *}$, Sudirikku Hennadige Padmal De Silva ${ }^{1}$, Rashan Haniffa ${ }^{2}$, Isurujith Kongala Liyanage ${ }^{3}$, Kosala Saroj Amarasiri Jayasinghe ${ }^{4}$, Prasad Katulanda ${ }^{4}$, Chandrika Neelakanthi Wijeratne ${ }^{5}$, Sumedha Wijeratne ${ }^{5}$ and Lalini Chandika Rajapakse ${ }^{1}$

\begin{abstract}
Introduction: Obesity is an increasing problem in South Asian countries and Sri Lanka is no exception. The socioeconomic determinants of obesity in Sri Lanka, and in neighbouring countries are inadequately described. Aim was to describe social, cultural and economic determinants of obesity in a representative sample from Kalutara District in Sri Lanka.

Methods: This was a cross sectional descriptive study conducted among adults aged 35-64 years. A representative sample was selected using stratified random cluster sampling method from urban, rural and plantation sectors of Kalutara District. Data were collected using a pre-tested questionnaire. A body mass index of $23.01 \mathrm{~kg} / \mathrm{m}^{2}-27.50 \mathrm{~kg} / \mathrm{m}^{2}$ was considered as overweight and $\geq 27.51 \mathrm{~kg} / \mathrm{m}^{2}$ as obese. Waist circumference (WC) of $\geq 90 \mathrm{~cm}$ and $\geq 80 \mathrm{~cm}$ was regarded as high for men and women respectively. Significance of prevalence of obesity categories across different socio-economic strata was determined by chi square test for trend.

Results: Of 1234 adults who were screened, age and sex adjusted prevalence of overweight, obesity and abdominal obesity (high WC) were 33.2\% (male 27.3\%/female 38.7\%), 14.3\% (male 9.2\%/female 19.2\%) and 33.6\% (male 17.7\%/ female 49.0\%) respectively. The Muslims had the highest prevalence of all three obesity categories. Sector, education, social status quintiles and area level deprivation categories show a non linear social gradient while income shows a linear social gradient in all obesity categories, mean BMI and mean WC. The differences observed for mean BMI and mean WC between the lowest and highest socioeconomic groups were statistically significant.

Conclusion: There is a social gradient in all three obesity categories with higher prevalence observed in the more educated, urban, high income and high social status segments of society. The higher socioeconomic groups are still at a higher risk of all types of obesity despite other public health indicators such as maternal and infant mortality displaying an established social gradient.
\end{abstract}

Keywords: Prevalence of obesity, Socioeconomic and cultural determinants of obesity, Obesity in plantation sector, Obesity in Muslims

\footnotetext{
* Correspondence: pubududesilva@ymail.com

'Department of Community Medicine, Faculty of Medicine, University of Colombo, Colombo, Sri Lanka

Full list of author information is available at the end of the article
} 


\section{Introduction}

The obesity epidemic is a worldwide public health problem [1,2]. It is a major risk factor for non-communicable diseases (NCDs) causing diabetes, cardiovascular disease, cancer and premature death $[1,3]$. In higher income countries (HICs) the overall prevalence of obesity among men and women were 18.2 - 19.9 and 21.2 - 23.2 respectively while in India, China and Sub Saharan African regions this varies from 1.8 to 3.1 and 3.9 to 10.7 respectively [4]. Although a high prevalence of obesity is observed in HICs a larger burden rests in lower income countries (LICs)/lower middle income countries (LMICs) as most of the obese (and nonobese) population resides in these countries [3-5]. Further these LICs/LMICs demonstrate a continual rise in obesity prevalence $[3,6]$.

The publications on obesity in other countries in the South Asian regions have not described in detail the correlations with social gradient. These were limited to associations of individual economic status and education with obesity [7-12]. The social gradients in obesity in HICs, give rise to inequalities in health outcomes and worsen the health of disadvantaged groups [13,14]. In order to tackle the burden of obesity it is important to understand the social determinants of obesity. Knowledge of obesity prevalence within social groups will provide insights into causal pathways and avenues for possible public health intervention. Any social gradient of obesity prevalence or its change from established patterns is important in any interventions directed towards minimising these conditions, especially as groups at the bottom of the social gradient already have established disadvantages in other spheres of well-being such as income, wealth or education [13]. Using a social determinants approach to obesity would provide an opportunity for sustainable and equitable outcomes [14].

We have published the findings of social determinants of diabetes mellitus in a representative sample from Kalutarta District, Sri Lanka [15]. We now describe in the same sample using additional data collected, the prevalence of obesity, and its socioeconomic and cultural determinants.

\section{Methods}

The detailed methodology of this cross sectional survey has already been described [15]. The study was conducted in Kalutara district (a district with urban, rural and estate population in Sri Lanka) among 35 to 64 year olds. A sample of 1300 was shown to be adequate to detect an overweight and central obesity prevalence of 25\% [7] with a margin of error at $3.5 \%$ and $\alpha$ error at $5 \%$ with consideration of $10 \%$ dropout rate and a cluster effect of 2 . A random, stratified cluster sampling method was used to select the participants. The first level of stratification was at urban, rural and estate sectors with rural and estate sectors being over sampled. The primary sampling unit was the Grama Niladari Division (GND), which is the lowest village level administrative division in Sri Lanka. The selection of GNDs within the sector was probability proportionate to the size of the 35 to 64 years population. Within the GNDs 20 households were randomly selected using the electoral registry and an eligible individual was selected randomly from each household. Pregnant and lactating females, institutionalized individuals and those on prolonged treatment with drugs known to cause diabetes mellitus were excluded.

The body weight was measured to the nearest $100 \mathrm{~g}$ with Virtual and Measurements Control model VW 320, electronic digital weighing scales. The body height was measured to the nearest $0.5 \mathrm{~cm}$ using "Seca microtoise" steel tapes. When measuring body height, the subjects were made to stand looking straight ahead with their head, back and feet touching the vertical support [16]. The measurements were taken from the ground to the uppermost position of the head while the person was in full inspiration. The waist circumference (WC) was measured to the nearest $0.2 \mathrm{~cm}$ using plastic flexible (non-elastic) measuring tapes. It was measured at the midway between the lower margin of the lowest rib and the upper margin of the iliac crest, at the end of a normal expiration [17].

All measurements were taken while the patient was in light indoor clothing, without footwear or items in pockets. All measuring instruments were calibrated (zero and span calibration) before use.

Anthropometric measurements were taken by five trained Public Health Nursing Sisters (PHNSs). The training was conducted at Medical Research Institute (MRI), Colombo. All five PHNSs were standardized for measuring weight, height and waist circumference. Using a block design the variation between instruments and observers were assessed simultaneously. A block consisted of five adults in the age group of 35 to 64 years. Each PHNS took measurement of weight, height and waist circumference in all five individuals using five different sets of measuring instruments. The mean scores of measurements of the five individuals were compared with the five PHNS and the five instruments.

Inter-observer reliability of anthropometric measurements was assessed by the Pearson's correlation coefficient (r). This was calculated for each of the anthropometric measures using the measurements made by the principal investigator and each PHNS.

The body mass index (BMI) was used as the indicator of general obesity while WC was used as the indicator of abdominal obesity. A BMI of $\leq 18.49 \mathrm{~kg} / \mathrm{m}^{2}$ was regarded as underweight, $18.50 \mathrm{~kg} / \mathrm{m}^{2}$ to $23.00 \mathrm{~kg} / \mathrm{m}^{2}$ as desirable, 
$23.01 \mathrm{~kg} / \mathrm{m}^{2}$ to $27.50 \mathrm{~kg} / \mathrm{m}^{2}$ as overweight and $\geq 27.51 \mathrm{~kg} / \mathrm{m}^{2}$ as obese [18]. WC of $\geq 90 \mathrm{~cm}$ and $\geq 80 \mathrm{~cm}$ was regarded as high for men and women respectively $[19,20]$.

Measures were taken to improve the quality and accuracy of data including training and standardization of data collectors, strict adherence to operations manuals and calibration of instruments [21].

The social status index developed by De Silva [21] and the Unsatisfactory Basic Needs Index (UBNI), an area level deprivation index for Sri Lanka, developed by Satharasinghe [22] were used. All results were weighted and adjusted for age and sex of the Sri Lankan population. Significance of prevalence across different socio-economic strata was determined by chi square test for trend.

Ethical approval was obtained from the Ethics review committee of the Faculty of Medicine, University of Colombo.

\section{Results}

Among the 1300 selected, 1234 (94.92\%) participated in the study. There were no significant differences between the observers $(\mathrm{p}=0.99)$ and between the instruments $(\mathrm{p}=0.99)$ (Additional file 1). The levels of agreements for weight, height and WC among the five PHNS were more than 0.78 for all the measurements representing good reliability (Additional file 2).

Overall age and sex adjusted prevalence of overweight, obesity and abdominal obesity were 33.2\% (391), 14.3\% (167) and 33.6\% (407) respectively. Table 1 describes the age and sex distribution of obesity categories, mean BMI and mean WC while the socioeconomic determinants of these are described in Table 2.

Obesity prevalence was significantly higher in females when compared to males in all three (overweight, obese and abdominal obesity) categories $(\mathrm{p}<0.001)$.

There was a social gradient for the prevalence of overweight, obesity, and abdominal obesity in the socioeconomic categories with chi square for trends being statistically significant $(\mathrm{p}<0.001)$. The mean BMI and WC show the same clear trend within sector, education, income, social status index and UBNI groups. The 95\%

Table 1 Age and sex distribution of obesity categories, BMI and WC among 35 to 64 year olds in Kalutara district

\begin{tabular}{|c|c|c|c|c|c|c|c|c|c|c|}
\hline \multirow[t]{3}{*}{ Age categories } & \multicolumn{6}{|c|}{ Obesity categories } & \multicolumn{2}{|c|}{ BMI $\left(\mathrm{kgm}^{-2}\right)$} & \multicolumn{2}{|c|}{$W C(\mathrm{~cm})$} \\
\hline & \multicolumn{2}{|c|}{ Overweight } & \multicolumn{2}{|l|}{ Obese } & \multicolumn{2}{|c|}{ Abdominal obesity } & \multirow[t]{2}{*}{ Mean } & \multirow[t]{2}{*}{$95 \% \mathrm{Cl}$} & \multirow[t]{2}{*}{ Mean } & \multirow[t]{2}{*}{$95 \% \mathrm{Cl}$} \\
\hline & Number & Percent & Number & Percent & Number & Percent & & & & \\
\hline \multicolumn{11}{|l|}{ Both genders } \\
\hline 35 to 39 Years $(n=186)$ & 53 & $30.2 \%$ & 32 & $39.4 \%$ & 62 & $33.0 \%$ & 22.4 & $21.59-23.30$ & 78.7 & $76.28-81.07$ \\
\hline 40 to 44 Years $(n=220)$ & 74 & $31.5 \%$ & 41 & $15.4 \%$ & 87 & $40.3 \%$ & 23.8 & $22.95-24.67$ & 81.1 & $79.07-83.21$ \\
\hline 45 to 49 Years $(n=213)$ & 86 & $44.0 \%$ & 25 & $13.6 \%$ & 80 & $37.5 \%$ & 23.6 & $22.79-24.33$ & 81.3 & $79.52-83.14$ \\
\hline 50 to 54 Years $(n=201)$ & 55 & $31.3 \%$ & 27 & $15.1 \%$ & 60 & $31.1 \%$ & 22.9 & $21.98-23.81$ & 79.8 & $77.68-81.85$ \\
\hline 55 to 59 Years $(n=224)$ & 64 & $29.0 \%$ & 30 & $12.6 \%$ & 71 & $28.0 \%$ & 22.7 & $21.87-23.55$ & 81.1 & $78.90-83.29$ \\
\hline 60 to 64 Years $(n=182)$ & 59 & $32.4 \%$ & 12 & $4.9 \%$ & 47 & $27.3 \%$ & 21.6 & $20.92-22.34$ & 78.0 & $75.95-79.95$ \\
\hline Total $(n=1226)$ & 391 & $33.2 \%$ & 167 & $14.3 \%$ & 407 & $33.6 \%$ & 22.9 & $22.70-23.18$ & 80.1 & $79.47-80.68$ \\
\hline \multicolumn{11}{|l|}{ Male } \\
\hline 35 to 39 Years $(n=107)$ & 31 & $28.6 \%$ & 12 & $7.5 \%$ & 24 & $17.2 \%$ & 21.5 & $20.78-22.29$ & 79.9 & $77.70-82.10$ \\
\hline 40 to 44 Years $(n=111)$ & 34 & $22.7 \%$ & 15 & $16.6 \%$ & 26 & $22.4 \%$ & 22.8 & $21.93-23.67$ & 82.2 & $79.97-84.39$ \\
\hline 45 to 49 Years $(n=104)$ & 43 & $34.4 \%$ & 6 & $4.6 \%$ & 27 & $16.4 \%$ & 22.0 & $21.39-22.60$ & 80.8 & $79.34-82.29$ \\
\hline 50 to 54 Years $(n=99)$ & 26 & $33.2 \%$ & 9 & $7.8 \%$ & 24 & $20.2 \%$ & 21.8 & $21.19-22.49$ & 80.3 & $78.30-82.37$ \\
\hline 55 to 59 Years $(n=111)$ & 36 & $22.3 \%$ & 9 & $10.8 \%$ & 24 & $14.6 \%$ & 21.9 & $21.22-22.58$ & 81.2 & $79.46-82.90$ \\
\hline 60 to 64 Years $(n=90)$ & 22 & $19.3 \%$ & 6 & $6.4 \%$ & 12 & $12.8 \%$ & 21.0 & $20.24-21.75$ & 80.1 & $78.21-82.08$ \\
\hline Total $(n=622)$ & 192 & $27.4 \%$ & 57 & $9.2 \%$ & 137 & $17.7 \%$ & 21.9 & $21.46-22.36$ & 80.8 & $79.57-82.01$ \\
\hline \multicolumn{11}{|l|}{ Female } \\
\hline 35 to 39 Years $(n=79)$ & 22 & $31.7 \%$ & 20 & $23.1 \%$ & 38 & $48.0 \%$ & 23.3 & $22.38-24.23$ & 77.5 & $74.92-80.02$ \\
\hline 40 to 44 Years $(n=109)$ & 40 & $39.3 \%$ & 26 & $21.6 \%$ & 61 & $55.9 \%$ & 24.7 & $23.79-25.59$ & 80.2 & $78.11-82.35$ \\
\hline 45 to 49 Years $(n=109)$ & 43 & $53.1 \%$ & 19 & $22.2 \%$ & 53 & $57.8 \%$ & 25.1 & $24.36-25.79$ & 81.8 & $79.94-83.70$ \\
\hline 50 to 54 Years $(n=102)$ & 29 & $29.5 \%$ & 18 & $21.9 \%$ & 36 & $41.5 \%$ & 23.9 & $22.92-24.83$ & 79.2 & $77.39-81.04$ \\
\hline 55 to 59 Years $(n=113)$ & 28 & $37.5 \%$ & 21 & $14.9 \%$ & 47 & $45.6 \%$ & 23.7 & $22.84-24.65$ & 81.0 & $78.50-83.49$ \\
\hline 60 to 64 Years $(n=92)$ & 37 & $43.3 \%$ & 6 & $3.7 \%$ & 35 & $39.3 \%$ & 22.2 & $21.40-22.91$ & 76.1 & $73.91-78.39$ \\
\hline Total $(n=604)$ & 199 & $38.7 \%$ & 110 & $19.2 \%$ & 270 & $49.0 \%$ & 23.9 & $23.40-24.44$ & 79.4 & $78.09-80.67$ \\
\hline
\end{tabular}


Table 2 The distribution of obesity categories, BMI and WC by selected socioeconomic factors among 35 to 64 year olds in Kalutara district

\begin{tabular}{|c|c|c|c|c|c|c|c|c|c|c|}
\hline \multirow[t]{3}{*}{ Characteristic } & \multicolumn{6}{|c|}{ Obesity categories } & \multicolumn{2}{|c|}{ BMI $\left(\mathrm{kgm}^{-2}\right)$} & \multicolumn{2}{|c|}{$W C(\mathrm{~cm})$} \\
\hline & \multicolumn{2}{|c|}{ Overweight } & \multicolumn{2}{|l|}{ Obese } & \multicolumn{2}{|c|}{ Abdominal obesity } & \multirow[t]{2}{*}{ Mean } & \multirow[t]{2}{*}{$95 \% \mathrm{Cl}$} & \multirow[t]{2}{*}{ Mean } & \multirow[t]{2}{*}{$95 \% \mathrm{Cl}$} \\
\hline & Number & Percent & Number & Percent & Number & Percent & & & & \\
\hline \multicolumn{11}{|l|}{ Ethnicity } \\
\hline Sinhalese & 292 & $33.3 \%$ & 122 & $13.5 \%$ & 309 & $32.9 \%$ & 22.8 & $22.49-23.21$ & 79.9 & 78.97-80.77 \\
\hline Tamil & 59 & $12.7 \%$ & 17 & $3.9 \%$ & 51 & $10.6 \%$ & 21.0 & $20.57-21.43$ & 75.9 & $73.32-78.58$ \\
\hline Muslim & 39 & $34.4 \%$ & 28 & $39.6 \%$ & 46 & $61.3 \%$ & 26.3 & $23.99-28.52$ & 87.5 & $81.66-93.27$ \\
\hline \multicolumn{11}{|l|}{ Sector } \\
\hline Urban & 146 & $38.0 \%$ & 74 & $22.2 \%$ & 169 & $46.9 \%$ & 24.0 & $23.58-24.46$ & 83.6 & $82.47-84.66$ \\
\hline Rural & 186 & $33.1 \%$ & 76 & $14.2 \%$ & 186 & $33.4 \%$ & 22.8 & $22.48-23.19$ & 80.1 & $79.17-81.06$ \\
\hline Plantation & 59 & $21.3 \%$ & 17 & $5.7 \%$ & 52 & $17.3 \%$ & 20.5 & $20.03-20.99$ & 73.2 & $71.93-74.52$ \\
\hline \multicolumn{11}{|l|}{ Education category } \\
\hline No schooling & 12 & $31.5 \%$ & 5 & $10.0 \%$ & 9 & $16.9 \%$ & 21.3 & $19.28-23.39$ & 74.6 & $70.12-79.12$ \\
\hline Grade 5 or below & 58 & $23.6 \%$ & 29 & $13.3 \%$ & 62 & $23.7 \%$ & 22.1 & $21.11-23.15$ & 77.9 & $75.52-80.32$ \\
\hline Grade 6 to 10 & 127 & $25.0 \%$ & 48 & $12.9 \%$ & 129 & $31.1 \%$ & 22.4 & $22.82-23.00$ & 79.4 & $77.84-81.00$ \\
\hline O/L to Grade 12 & 112 & $39.7 \%$ & 44 & $15.8 \%$ & 109 & $37.8 \%$ & 23.5 & $22.81-24.23$ & 80.6 & $79.14-82.17$ \\
\hline $\mathrm{A} / \mathrm{L}$ and above & 61 & $43.3 \%$ & 25 & $13.2 \%$ & 69 & $39.6 \%$ & 23.4 & $22.67-24.20$ & 83.0 & $80.71-85.25$ \\
\hline \multicolumn{11}{|l|}{ Occupation category } \\
\hline Professional & 5 & $21.5 \%$ & 1 & $0.6 \%$ & 4 & $2.3 \%$ & 22.1 & $21.57-22.70$ & 80.1 & $74.76-85.38$ \\
\hline Technical \& clerical & 21 & $45.9 \%$ & 11 & $12.1 \%$ & 24 & $34.3 \%$ & 23.6 & $22.43-24.86$ & 83.9 & $80.18-87.64$ \\
\hline Vendors \& sellers & 48 & $27.7 \%$ & 25 & $18.6 \%$ & 53 & $33.2 \%$ & 23.2 & $22.20-24.25$ & 84.7 & $81.94-87.41$ \\
\hline Skilled manual workers & 61 & $23.3 \%$ & 21 & $8.4 \%$ & 44 & $15.0 \%$ & 21.4 & $20.70-22.07$ & 77.9 & $76.16-79.66$ \\
\hline Unskilled manual workers & 50 & $24.9 \%$ & 13 & $2.2 \%$ & 36 & $8.5 \%$ & 20.9 & $19.97-21.76$ & 75.6 & $73.29-77.89$ \\
\hline Retired & 24 & $39.2 \%$ & 4 & $7.4 \%$ & 13 & $11.0 \%$ & 22.6 & $21.46-23.67$ & 83.3 & $80.44-86.07$ \\
\hline Unemployed & 17 & $21.1 \%$ & 1 & $7.2 \%$ & 11 & $19.4 \%$ & 21.8 & $20.01-23.67$ & 80.2 & $76.22-84.16$ \\
\hline Housewife & 151 & $39.8 \%$ & 83 & $19.5 \%$ & 205 & $52.4 \%$ & 24.0 & $23.45-24.64$ & 79.9 & $78.47-81.36$ \\
\hline \multicolumn{11}{|c|}{ Income category (Rs. per month) } \\
\hline$<10,000$ & 118 & $28.8 \%$ & 39 & $12.7 \%$ & 104 & $29.5 \%$ & 22.4 & $21.65-23.05$ & 78.1 & $76.36-79.76$ \\
\hline 10,000 to 30,000 & 211 & $34.7 \%$ & 96 & $13.5 \%$ & 224 & $34.2 \%$ & 23.0 & $22.54-23.40$ & 80.7 & $79.52-81.87$ \\
\hline$>30,000$ & 50 & $35.4 \%$ & 27 & $18.0 \%$ & 66 & $40.3 \%$ & 23.7 & $22.83-24.66$ & 81.6 & 79.34-83.84 \\
\hline \multicolumn{11}{|l|}{ Social status index } \\
\hline 1st quintile (richest) & 89 & $34.2 \%$ & 42 & $19.9 \%$ & 103 & $43.0 \%$ & 23.8 & $23.97-24.55$ & 81.2 & $79.51-82.99$ \\
\hline 2nd quintile & 91 & $37.2 \%$ & 41 & $12.5 \%$ & 96 & $33.3 \%$ & 22.8 & $22.09-23.48$ & 79.9 & $78.17-81.70$ \\
\hline 3rd quintile & 81 & $32.3 \%$ & 35 & $12.4 \%$ & 79 & $29.6 \%$ & 22.6 & $21.90-23.21$ & 79.6 & $77.70-81.44$ \\
\hline 4th quintile & 77 & $28.1 \%$ & 37 & $12.3 \%$ & 88 & $30.2 \%$ & 22.7 & $21.97-23.41$ & 79.7 & $77.91-81.51$ \\
\hline 5th quintile (poorest) & 43 & $17.6 \%$ & 10 & $4.3 \%$ & 35 & $13.7 \%$ & 20.1 & $19.57-20.57$ & 72.3 & $70.95-73.67$ \\
\hline \multicolumn{11}{|c|}{ Unsatisfactory basic needs index } \\
\hline 1 (poorest) & 23 & $26.8 \%$ & 3 & $4.9 \%$ & 17 & $15.6 \%$ & 21.4 & $20.08-22.71$ & 78.0 & $74.91-81.14$ \\
\hline 2 & 38 & $10.5 \%$ & 13 & $15.7 \%$ & 39 & $31.9 \%$ & 21.6 & $19.93-23.36$ & 77.5 & $71.74-83.29$ \\
\hline 3 & 67 & $32.3 \%$ & 25 & $12.6 \%$ & 52 & $26.7 \%$ & 22.8 & $22.20-23.38$ & 79.7 & $78.17-81.33$ \\
\hline 4 & 99 & $34.8 \%$ & 49 & $11.9 \%$ & 120 & $33.9 \%$ & 22.5 & $21.91-23.18$ & 79.2 & $77.64-80.56$ \\
\hline 5 (richest) & 164 & $36.9 \%$ & 77 & $20.2 \%$ & 179 & $44.9 \%$ & 24.0 & $23.27-24.67$ & 82.0 & $80.35-83.62$ \\
\hline
\end{tabular}


Table 3 Multivariate analysis of obesity categories with selected socioeconomic factors among 35 to 64 year olds in Kalutara district

\begin{tabular}{|c|c|c|c|c|c|c|}
\hline \multirow[t]{3}{*}{ Characteristic } & \multicolumn{6}{|c|}{ Obesity categories } \\
\hline & \multicolumn{2}{|l|}{ Overweight } & \multicolumn{2}{|l|}{ Obese } & \multicolumn{2}{|c|}{ Abdominal obesity } \\
\hline & Odds ratio & $\begin{array}{l}95 \% \text { Confidence } \\
\text { interval }\end{array}$ & Odds ratio & $\begin{array}{l}95 \% \text { Confidence } \\
\text { interval }\end{array}$ & Odds ratio & $\begin{array}{l}95 \% \text { Confidence } \\
\text { interval }\end{array}$ \\
\hline \multicolumn{7}{|l|}{ Age categories } \\
\hline 35 to 39 Years & 1 & & 1 & & 1 & \\
\hline 40 to 44 Years & 1.37 & $0.66-2.82$ & 1.19 & $0.55-2.58$ & 1.43 & $0.76-2.72$ \\
\hline 45 to 49 Years & $2.63^{*}$ & $1.23-5.61$ & 0.88 & $0.36-2.14$ & 1.62 & $0.79-3.30$ \\
\hline 50 to 54 Years & 1.55 & $0.71-3.40$ & 0.92 & $0.38-2.24$ & 1.15 & $0.53-2.49$ \\
\hline 55 to 59 Years & 1.16 & $0.54-2.49$ & 0.62 & $0.23-1.67$ & 1.07 & $0.50-2.31$ \\
\hline 60 to 64 Years & 1.18 & $0.53-2.65$ & 0.21 & $0.05-0.83$ & 0.94 & $0.43-2.04$ \\
\hline \multicolumn{7}{|l|}{ Sex } \\
\hline Male & 1 & & 1 & & 1 & \\
\hline Female & 1.13 & $0.51-2.49$ & $3.58^{*}$ & $1.15-11.15$ & 2.28 & $0.94-5.56$ \\
\hline \multicolumn{7}{|l|}{ Ethnicity } \\
\hline Sinhalese & 3.63 & $0.88-15.04$ & 0.45 & $0.02-10.29$ & 1.95 & $0.32-11.73$ \\
\hline Tamil & 1 & & 1 & & 1 & \\
\hline Muslim & $8.04^{*}$ & $1.37-47.10$ & 1.82 & $0.08-43.66$ & 6.18 & $0.82-46.41$ \\
\hline \multicolumn{7}{|l|}{ Sector } \\
\hline Urban & 0.08 & $0.01-0.48$ & 1.15 & $0.05-26.77$ & 0.19 & $0.03-1.27$ \\
\hline Rural & 0.06 & $0.01-0.34$ & 0.96 & $0.04-22.78$ & 0.15 & $0.02-0.97$ \\
\hline Plantation & 1 & & 1 & & 1 & \\
\hline \multicolumn{7}{|l|}{ Education category } \\
\hline No schooling & 1 & & 1 & & 1 & \\
\hline Grade 5 or below & 1.22 & $0.27-5.53$ & 3.14 & $0.24-41.86$ & 3.93 & $0.51-30.57$ \\
\hline Grade 6 to 10 & 1.10 & $0.26-4.57$ & 2.66 & $0.21-34.17$ & 6.36 & $0.84-48.11$ \\
\hline $\mathrm{O} / \mathrm{L}$ to Grade 12 & 2.77 & $0.65-11.76$ & 2.89 & $0.21-39.46$ & $8.39^{*}$ & $1.09-64.71$ \\
\hline $\mathrm{A} / \mathrm{L}$ and above & 2.59 & $0.56-11.90$ & 2.29 & $0.16-32.34$ & $10.82^{*}$ & $1.34-87.44$ \\
\hline \multicolumn{7}{|l|}{ Occupation category } \\
\hline Professional & 0.98 & $0.08-12.23$ & 0.39 & $0.01-11.34$ & 0.20 & $0.02-1.84$ \\
\hline Technical \& clerical & 1.49 & $0.41-5.41$ & 7.06 & $0.65-76.55$ & 4.24 & $0.78-23.04$ \\
\hline Vendors \& sellers & 1.05 & $0.37-2.96$ & $16.27^{*}$ & $2.22-119.46$ & $6.67^{*}$ & $1.53-29.13$ \\
\hline Skilled manual workers & 0.72 & $0.28-1.89$ & $7.13^{*}$ & $1.01-50.65$ & 2.88 & $0.69-12.12$ \\
\hline Unskilled manual workers & 1 & & 1 & & 1 & \\
\hline Retired & 1.22 & $0.33-4.52$ & 10.92 & $0.91-131.04$ & 1.46 & $0.24-8.70$ \\
\hline Unemployed & 0.81 & $0.20-3.35$ & 1 & & 2.06 & $0.28-15.31$ \\
\hline Housewife & 2.18 & $0.78-6.08$ & 6.20 & $0.81-47.37$ & $8.29^{*}$ & $2.35-29.28$ \\
\hline \multicolumn{7}{|c|}{ Income category (Rs. per month) } \\
\hline$<10,000$ & 1 & & 1 & & 1 & \\
\hline 10,000 to 30,000 & 1.02 & $0.63-1.66$ & 0.96 & $0.50-1.85$ & 1.16 & $0.71-1.90$ \\
\hline$>30,000$ & 1.23 & $0.56-2.69$ & 2.36 & $0.88-6.31$ & $2.38^{*}$ & $1.1-5.17$ \\
\hline \multicolumn{7}{|l|}{ Social status index } \\
\hline 1st quintile (richest) & $4.82^{*}$ & $1.12-20.76$ & 3.57 & $0.61-20.78$ & 1.95 & $0.51-7.45$ \\
\hline 2nd quintile & $4.77^{*}$ & $1.17-19.41$ & 2.40 & $0.44-13.02$ & 1.76 & $0.48-6.48$ \\
\hline 3rd quintile & $4.92^{*}$ & $1.22-19.90$ & 2.32 & $0.44-12.57$ & 1.84 & $0.52-6.52$ \\
\hline
\end{tabular}


Table 3 Multivariate analysis of obesity categories with selected socioeconomic factors among $\mathbf{3 5}$ to 64 year olds in Kalutara district (Continued)

\begin{tabular}{|c|c|c|c|c|c|c|}
\hline 4th quintile & $3.75^{*}$ & $1.15-12.21$ & 3.11 & $0.77-12.57$ & 2.84 & $0.99-8.15$ \\
\hline 5th quintile (poorest) & 1 & & 1 & & 1 & \\
\hline \multicolumn{7}{|c|}{ Unsatisfactory basic needs index } \\
\hline 1 (poorest) & 1 & & 1 & & 1 & \\
\hline 2 & 0.28 & $0.06-1.41$ & 3.85 & $0.47-31.73$ & 3.00 & $0.68-13.26$ \\
\hline 3 & 1.33 & $0.54-3.28$ & 3.36 & $0.70-16.19$ & 2.59 & $0.97-6.90$ \\
\hline 4 & 1.50 & $0.60-3.76$ & 2.31 & $0.45-11.87$ & $3.36^{*}$ & $1.20-9.39$ \\
\hline 5 (richest) & 1.47 & $0.55-3.95$ & 3.52 & $0.68-18.15$ & $4.60^{*}$ & $1.60-13.25$ \\
\hline
\end{tabular}

confident intervals of BMI and WC do not overlap for highest and lowest groups in most of these socioeconomic factors.

Table 3 describes the multivariate analysis of obesity categories with selected socioeconomic factors.

Figure 1 illustrates the distribution of BMI in relation to income and diabetes status while Figure 2 demonstrates the distribution of WC in relation income and diabetes status. The mean BMI and WC show a linear social gradient among income categories in non-diabetics.

\section{Discussion}

Our paper demonstrates that the prevalence of obesity in Kalutara District is higher than previously reported figures for Sri Lanka, with evidence to support a rising trend, and that obesity categories show a non linear social gradient with the highest effected groups being females, urban dwellers, the high socio economic category, and the Muslim community.

The response rate of study participants was high (94.4\%) and thus the participation bias is kept minimal. The study sample was comparable (age groups and gender) to the study population in Kalutara district [15]. The variations between instruments and observers for anthropometric measurements and the levels of agreements were acceptable [23].

Our prevalence for overweight, obesity and central obesity $(33.2 \%, 14.2 \%$ and $33.6 \%)$ are higher than previously reported studies (though using slightly different criteria for obesity categorization) in Sri Lanka and the trend for increase persists [7,24-26]. The early studies in 1990 reported obesity rates of $7 \%$ for males and $13.4 \%$ for females while in 2006, the prevalence rates of overweight, obesity and central obesity were $25.2 \%, 9.2 \%$ and $26.2 \%[7,24$,$] . Some of these studies were limited to$ small sample sizes in a few regions [24,27]. Larger studies conducted in 2005/6 showed a high burden of obesity, with especially high proportions observed among females of all age categories and in the urban sector $[7,25]$. The female preponderance of obesity in Sri Lanka may contribute to the high prevalence of non-communicable diseases amongst women [28].

The prevalence of obesity shows wide variation in the South Asian region. The reported figures for Bangladesh were lesser than Sri Lankan figures [11]. Pakistani rates for overweight and obesity (28.2\% for females $22 \%$ for males) are similar to our findings [12]. In South India the prevalence of obesity and abdominal obesity ranged from $35.1 \%$ to $56.2 \%$ among males and females which were higher than our figures [29]. Prevalence rates of overweight and obesity reported in Nepal (59.1\% for males and $61.8 \%$ for females) and Maldives (60.8\% of males and $65.5 \%$ of females) were much higher than our findings $[8,10]$.

With regard to socio economic status and obesity Katulanda demonstrated increasing odds ratios for obesity with increasing income levels similar to our findings [7]. Similar findings were observed for the prevalence of diabetes mellitus and impaired glucose tolerance in Sri Lanka in 1993 and in 2012 even as Sri Lanka moved from a LIC to a LMIC $[15,27,30]$.

Higher prevalence of obesity was seen in low socio economic strata for HICs while the reverse was observed in LICs and LMICs [31]. Obesity occurring in developing countries was shown to affect the affluent [3]. South Asian settings show mixed results. Pakistan being a LMIC demonstrates a gradient for economic status, of lesser magnitude in comparison with our findings, for overweight and obesity [12]. India and Bangladesh similarly shows an increase in obesity prevalence with increase in education and standard of living index $[9,11]$. Nepal and Maldives reveals higher prevalence of overweight and obesity in lower educated groups while showing a clear social gradient for diabetes, hypertension and metabolic syndrome $[8,10]$. Epidemiological transitions were observed in Brazil where higher obesity prevalence observed among richest quintile was revered to the poorest quintile, in Sri Lanka such a change has not been observed for the past three decades despite its move from a LIC to a LMIC [30,32]. 


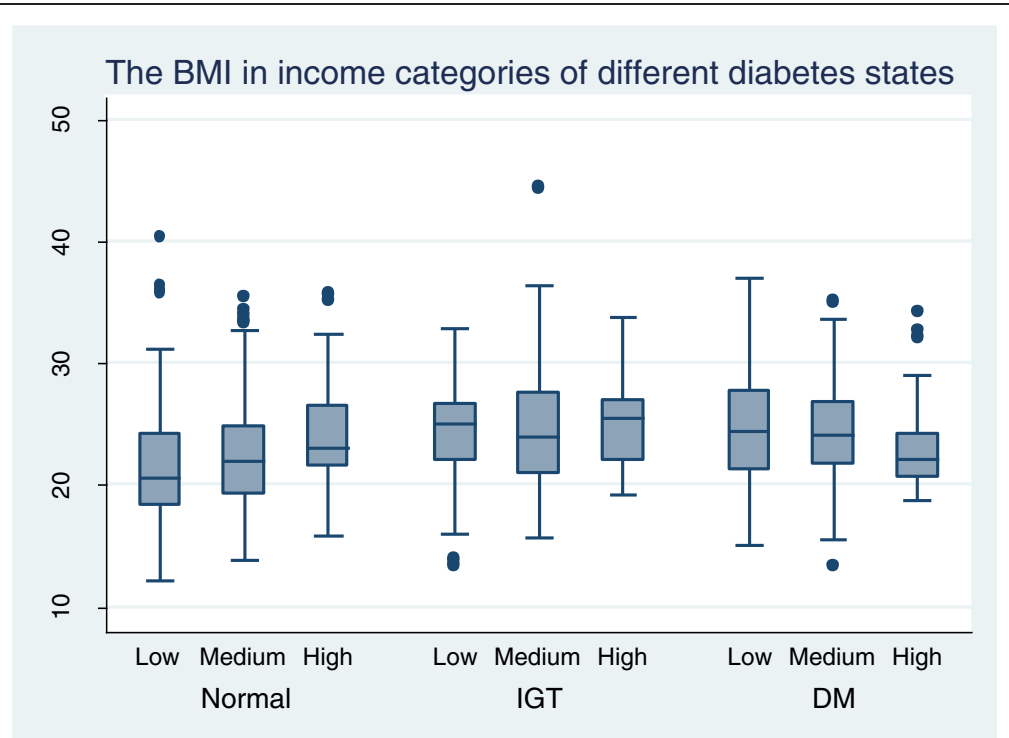

Figure 1 The distribution of BMI in relation to income and diabetes status among 35 to 64 year olds in Kalutara district.

The higher prevalence of obesity in Muslim communities may indicate social and cultural practices that influence lifestyle and diet. This was not demonstrated in the two large surveys on obesity conducted in $2005 / 6$ [7,25,]. However this is consistent with the high prevalence of diabetes and metabolic syndrome observed among Muslims in Sri Lanka [15,33]. Similarly in HICs high prevalence rates for obesity and diabetes was demonstrated among Asian migrants from Muslim countries [34,35]. Ethnicity and culture have not been explored as a risk factor in other South Asian countries.
Social gradient of obesity may contribute to the social gradient of NCDs. This is already observed with regard to diabetes mellitus including in Sri Lanka [15]. Those of higher socio economic status may access the limited healthcare facilities more than the lower categories and thus any regressive disparity in resource allocations may be exaggerated. This would in turn give rise to more complications and poor control of NCDs among the lower socioeconomic categories. This may explain the observed linear social gradient for mean BMI and mean WC among those with diabetes mellitus, possibly due to a more active response to illness by the higher socio economic group.

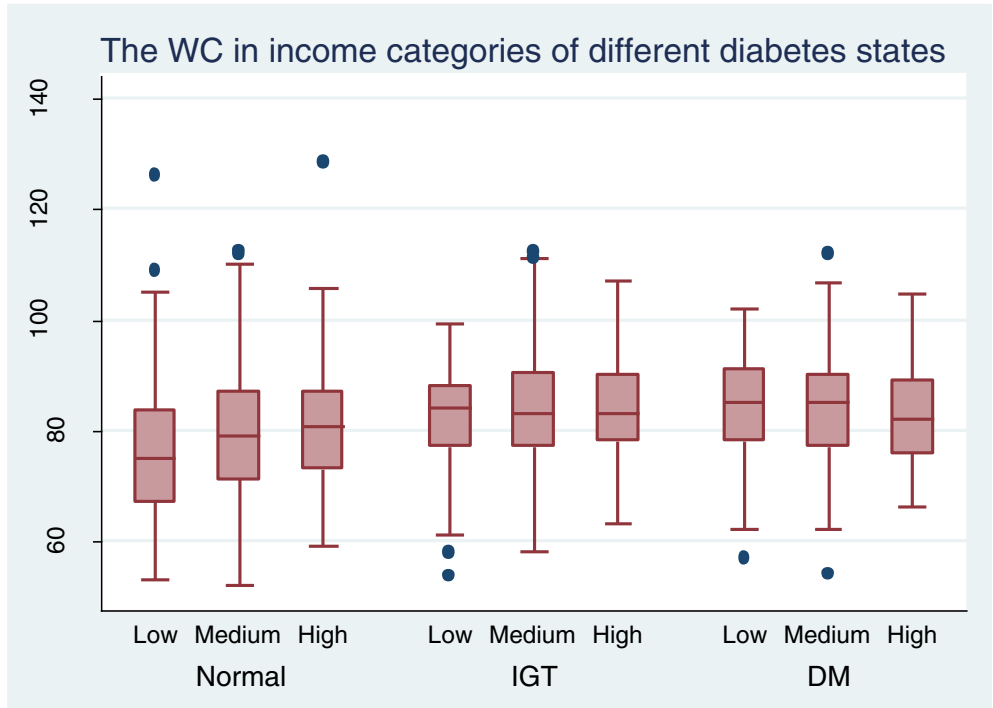

Figure 2 The distribution of WC in relation to income and diabetes status among 35 to 64 year olds in Kalutara district. 
If economic growth continues, with the cessation of war and increased overseas investment, and the middle class expands, a larger proportion of the population may then be exposed to these risk factors with consequent increase in obesity and NCD rates [32]. NCD prevention in Sri Lanka should target all socio economic categories with higher emphasis on the wealthy, females and Muslim communities.

\section{Conclusion}

Obesity in Kalutara District is higher among females, urban dwellers, high socio economic groups and in the Muslim community. A non linear social gradient of overweight, obesity and abdominal obesity is observed for education level, social status index levels, sector of residence and UBNI groups while income categories display a linear social gradient.

\section{Supplementary information}

Supplementary information is available at http://www. nature.com/ijo/index.html.

\section{Additional files}

Additional file 1: Reliability assessment of anthropometric measurements.

Additional file 2: Inter-observer reliability of anthropometric measurements.

\section{Abbreviations}

BMI: Body Mass Index; HIC: High Income Country; LIC: Low Income Country; LMIC: Lower Middle Income Country; NCD: Non Communicable Diseases; PHNS: Public Health Nursing Sister; UBNI: Unsatisfactory Basic Needs Index; WC: Waist circumference.

\section{Competing interests}

The authors declare that they have no competing interests.

\section{Authors' contributions}

APDS gave the original idea, developed the methodology, conducted the training and validation of data collection, data analysis and writing of the manuscript. SHPDS developed the methodology, supervised data collection, conducted analysis and writing the manuscript. RH developed the methodology, data analysis and writing of the manuscript. IKL developed the methodology, supervised data collection, conducted analysis and writing the manuscript. KSAJ also gave the original idea, developed the methodology, data analysis and writing of the manuscript. PK developed the methodology, data analysis and writing of the manuscript.CNW developed the methodology, data analysis and writing of the manuscript. SW developed the methodology, data analysis and writing of the manuscript. LCR also gave the original idea, developed the methodology, data analysis and writing of the manuscript. All authors read and approved the final manuscript.

\section{Acknowledgement}

A. Pubudu De Silva, S.H. Padmal De Silva and Isurujith K. Liyanage were supported by the ASCEND Program (www.med.monash.edu.au/ascend) funded by the Fogarty International Centre, National Institutes of Health, under Award Number: D43TW008332. The views of this publication are solely those of the authors and do not necessarily represent the official views of the National Institutes of Health or the ASCEND Program.
The authors acknowledge the assistance provided by the Medical Research Institute, Colombo, National Institute of Health Sciences, Kalutara and the Medical Officers of Health, Kalutara District.

\section{Author details}

${ }^{1}$ Department of Community Medicine, Faculty of Medicine, University of Colombo, Colombo, Sri Lanka. ${ }^{2}$ Centre for Tropical Medicine, University of Oxford, Oxford, UK. ${ }^{3}$ Department of Para Clinical Sciences, Faculty of Medicine, General Sir John Kotelawala University, Ratmalana, Sri Lanka. ${ }^{4}$ Department of Clinical Medicine, Faculty of Medicine, University of Colombo, Colombo, Sri Lanka. ${ }^{5}$ Department of Obstetrics \& Gynaecology, Faculty of Medicine, University of Colombo, Colombo, Sri Lanka.

Received: 21 October 2014 Accepted: 12 January 2015

Published online: 17 January 2015

\section{References}

1. Haslam DW, James WPT. Obesity. Lancet. 2005;366:1197-209.

2. Prentice AM. The emerging epidemic of obesity in developing countries. Int J Epidemiol. 2006;35:93-6.

3. Caballero B. The Global Epidemic of Obesity: An Overview. Epidemiol Rev. 2007;29:1-5.

4. Kelly T, Yang W, Chen C-S, Reynolds K, He J. Global burden of obesity in 2005 and projections to 2030. Int J Obes. 2008;32:1431-7.

5. Hossain P, Kawar B, Nahas EM. Obesity and diabetes in the developing world - a growing challenge. N Engl J Med. 2007;356:213-5.

6. Ghaffar A, Reddy KS, Singhi M. Burden of non-communicable diseases in South Asia. Br Med J. 2004;328:807-10.

7. Katulanda P, Jayawardena MAR, Sheriff MHR, Constantine GR, Matthews DR. Prevalence of overweight and obesity in Sri Lankan adults. Obes Rev. 2010;11:751-6.

8. Aboobakur M, Latheef A, Mohamed AJ, Moosa S, Pandey RM, Krishnan A, et al. Surveillance for non-communicable disease risk factors in Maldives: results from the first STEPS survey in Male. Int J Public Health. 2010;55:489-96.

9. Subramanian SV, Kawachi I, Smith GD. Income inequality and the double burden of under- and overnutrition in India. J Epidemiol Community Health. 2007;61:802-9.

10. Sharma SK, Ghimire A, Radhakrishnan J, Thapa L, Shrestha NR, Paudel N, et al. Prevalence of hypertension, obesity, diabetes, and metabolic syndrome in Nepal. Int J Hypertens. 2011;2011:821971.

11. Razzaque A, Nahar L, Van Minh H, Ng N, Juvekar S, Ashraf A, et al. Social factors and overweight: Evidence from nine Asian INDEPTH Network sites. Glob Health Action. 2009:2:54-9.

12. Jafar TH, Chaturvedi N, Pappas G. Prevalence of overweight and obesity and their association with hypertension and diabetes mellitus in an Indo-Asian population. Can Med Assoc J. 2006;175:1071-7.

13. Marmot M. Social determinants of health inequalities. Lancet. 2005;365:1099-104.

14. Commission on Social Determinants of Health. Achieving health equity: from root causes to fair outcomes. Geneva: World Health Organization; 2007.

15. De Silva AP, De Silva SHP, Liyanage IK, Rajapakse LC, Jayasinghe KSA, Katulanda P, et al. Social, cultural and economical determinants of diabetes mellitus in Kalutara district, Sri Lanka: a cross sectional descriptive study. Int J Equity Health. 2012;11:76.

16. Centers for Disease Control and Prevention. National Health and Nutrition Examination Survey (NHANES): Anthropometry Procedures Manual. Atlanta: Centers for Disease Control and Prevention; 2007.

17. Lean MEJ, Han TS, Morrison CE. Waist circumference as a measure for indicating need for weight management. Br Med J. 1995;311:158-61.

18. World Health Organization. Appropriate body-mass index for Asian populations and its implications for policy and intervention strategies. Lancet. 2004;363:157-63.

19. Misra A, Vikram NK, Gupta R, Pandey RM, Wasir JS, Gupta VP. Waist circumference cutoff points and action levels for Asian Indians for identification of abdominal obesity. Int J Obes. 2006;30:106-11.

20. The International Obesity Task Force. The Asia-Pacific perspective: redefining obesity and its treatment. Sydney: Health Communications Australia; 2000.

21. De Silva AP. Social Determinants of Diabetes Mellitus in Kalutara District. In: MD thesis. University of Colombo, Postgraduate Institute of Medicine. 2010

22. Satharasinghe A. Census Department Classifies GN Divisions by Poverty. Colombo: Department of Census and Statistics; 2008. 
23. Goto R, Mascie-Taylor CGN. Precision of Measurement as a Component of Human Variation. J Physiol Anthropol. 2007;26:253-6.

24. Malavige GN, De Alwis NM, Weerasooriya N, Fernando DJ, Siribaddana SH. Increasing diabetes and vascular risk factors in a sub-urban Sri Lankan population. Diabetes Res Clin Pract. 2002;57:143-5.

25. Wijewardena K, Mohideen MR, Mendis S, Fernando DS, Kulathilaka T, Weerasekara D, et al. Prevlance of hypertension, diabetes and obesity: baseline findings of a population based survey in four provinces in Sri Lanka. Ceylon Med J. 2005;50:62-70.

26. Fernando DJS, Siribaddana SH, De Silva DR, Perera SD. The prevalence of obesity and other coronary risk factors in a suburban Sri Lankan community. Asia Pacific J Clin Nutr. 1994;3:155-9.

27. Illangasekara U. The epidemiology of diabetes in Sri Lanka; Bibile memorial oration. Sri Lanka J Med. 1998;7:13-21.

28. Department of Health. Annual Health Bulletin 2003. Colombo: Department of Health; 2006.

29. Deepa M, Faroog S, Deepa R, Manjula D, Mohan V. Prevalence and significance of generalized and central body obesity in an urban Asian Indian population in Chennai, India (CURES: 47). Eur J Clin Nutr. 2009;63:259-67.

30. The World Bank: The World Bank Data: Sri Lanka [http://data.worldbank.org/ country/sri-lanka]

31. McLaren L. Socioeconomic Status and Obesity. Epidemiol Rev. 2007;29:29-48.

32. Monteiro CA, Conde WL, Popkin BM. The burden of disease from undernutrition and overnutrition in countries undergoing rapid nutrition transition: a view from Brazil. Am J Public Health. 2004;94:433-4.

33. Katulanda $P$, Ranasinghe $P$, Jayawardana $R$, Sheriff $R$, Matthews DR Metabolic syndrome among Sri Lankan adults: prevalence, patterns and correlates. Diabetol Metabol Syndr. 2012:4:24.

34. National Obesity Observatory. Obesity and ethnicity. London: National Health Services; 2011

35. Barnett AH, Dixon AN, Bellary S, Hanif MW, O'Hare JP, Raymond NT, et al. Type 2 diabetes and cardiovascular risk in the UK south Asian community. Diabetologia. 2006;49:2234-46.

\section{Submit your next manuscript to BioMed Central and take full advantage of:}

- Convenient online submission

- Thorough peer review

- No space constraints or color figure charges

- Immediate publication on acceptance

- Inclusion in PubMed, CAS, Scopus and Google Scholar

- Research which is freely available for redistribution 